\title{
Defined Observation Result Target Anatomic Site Laterality Code
}

National Cancer Institute

\section{Source}

National Cancer Institute. Defined Observation Result Target Anatomic Site Laterality

Code. NCl Thesaurus. Code C93783.

A coded value specifying the side of the body (or a paired organ) that is a target site for a procedure. 